\title{
LA INFLUENCIA DE LA SOCIEDAD EUGÉNICA MEXICANA EN LA EDUCACIÓN Y EN LA MEDICINA SOCIAL
}

\author{
Lara Suárez y López Guazo \\ Profesora Titular del Colegio de Ciencias y Humanidades \\ Laboratorio de Historia de la Biología - Facultad de Ciencias - UNAM (México)
}

\section{RESUMEN}

Este estudio sobre México y su Sociedad Eugénica intenta demostrar la relación entre el pensamiento biológico y médico y la sociedad y la compleja situación política vivida por el país a lo largo de la primera mitad del siglo XX. Se analiza también la legislación que se intentaba establecer en relación con los problemas surgidos de la existencia de una ampliación población indígena y mestiza, que muchos eugenistas deseaban «blanquear».

\section{SUMMARY}

This study on Mexico and their Eugenics Society tries to demostrate the relationship between the biological and medical thought and its relationship with the complex political situation lived by the country along the first half of the XX century. The legislation is also analyzed, legislation that was tried to establish in connection with the problems arisen from the existence of a wide indigenous and mestizo population, that many eugenic suppoters wanted to «bleach»

\section{MÉXICO EN LOS INICIOS DEL SIGLO XX.}

La Revolución Mexicana, que caracteriza la década de los años 1910-1920, se expresó con claridad en sucesos de gran violencia y participación política organizada, que transformaron el panorama conservador existente durante la dictadura de Porfirio Díaz, quien se mantuvo en el poder durante tres décadas — de 1878 hasta 1911— tiempo en el que conformó un sólido sistema político. El grupo que sostenía a Díaz, constituído por la oligarquía nacional, fundamentalmente representada por intelectuales criollos, favoreció la penetración masiva de capitales extranjeros con amplias facilidades para usufructuar los recursos naturales, bajo la premisa de que dichas concesiones representaban la alternativa para el progreso de México. 
Los principales focos de oposición durante el porfiriato fueron básicamente el campo y la industria. Los obreros, que entonces no representaban un grupo con poder político, atomizados y desorganizados, sufrieron fuertes golpes en los escasos movimientos de huelga que impulsaron. Es, entre otros, el caso de la huelga de los mineros de Cananea en 1906, en el norteño Estado de Sonora, que fue aplastada por Díaz con el apoyo e intervención de soldados estadounidenses, ya que los intereses económicos afectados eran de ciudadanos de ese país. Por otro lado, la problemática del campo en tiempos de Díaz, era provocada en gran medida por la estructura agraria. Las haciendas, latifundios de extensión considerable, habían provocado la desaparición de la pequeña propiedad campesina y las tierras pertenecientes a las comunidades indígenas. Así, tanto los pequeños campesinos como la clase media, que tenían interés en la posesión de las tierras ya ocupadas por los latifundistas, jugaron en buena medida un papel central en la orientación ideológica de la Revolución. La inconformidad tanto del sector industrial como del campesinado, cobró fuerza con el surgimiento del Partido Liberal Mexicano constituído primordialmente por intelectuales, cuya limitada e inmediata bandera política se restringía a la «no reelección», a pesar de que su ideario político coincidía con otras múltiples banderas que flotaban en el ambiente en el momento de la derrota del régimen porfirista. Otros grupos de corte anarquista y socialista de la época no obtuvieron un consenso importante, situación que se refleja en la Constitución de 1917.

La mayoría de las obras más importantes respecto a la situación de México durante la última década del porfiriato, señalan como problemas fundamentales la necesidad apremiante de la reforma agraria y el cambio en el rumbo político ${ }^{1}$ y aunque varias se publicaron en las postrimerías de la dictadura de Díaz, evidencian las dos vertientes ideológicas que sustentan los dos grupos que ejercieron gran influencia en el desarrollo del proceso revolucionario ${ }^{2}$ : el cambio político en la obra de Madero y los cambios inaplazables respecto a la cuestión agraria con un enfoque positivista spenceriano, por parte de Molina Enríquez ${ }^{3}$.

La oligarquía científica mexicana empleaba el racismo spenceriano para fundamentar, en la primera década de nuestro siglo, la continuidad de la dictadura de Porfirio Díaz, quien les permitió conservar su posición privilegiada que: «... los blancos o los blanqueados prominentes como el mestizo Porfirio Díaz eran más aptos... ya que

1 MADERO, Francisco I., (1908), La sucesión presidencial en 1910, San Pedro, Coahuila, México.

2 MOLINA ENRíQUEZ, Andrés, (1909), Los grandes problemas nacionales, Ed. A. Carranza e Hijos, México.

3 Moreno de los ARCos, R., (1986), Ensayos de historia de la ciencia y la tecnología en México, UNAM, Instituto de Investigaciones Históricas, México. pp. 144-145. 


\section{LA INFLUENCIA DE LA SOCIEDAD EUGÉNICA MEXICANA EN LA EDUCACIÓN}

los indios habían de sucumbir en la lucha por la vida, por lo que la mejor forma de hacer progresar a México, era, por consiguiente con colonos europeos ${ }^{4} »$.

Es claro que durante el porfiriato, el grupo de los científicos adoptó al positivismo como instrumento ideológico al servicio de sus prerrogativas políticas y sociales. Emilio Rabasa y Justo Sierra, emplean así las tesis evolucionistas para justificar y legitimar «científicamente», tanto la concentración de la riqueza y del poder, como la existencia de millones de indígenas desposeídos de sus tierras, carentes de empleo y sin educación ${ }^{5}$. Rabasa sostenía que no a todos los mexicanos les era posible disfrutar de la educación, ya que la población se encontraba dividida en «capaces», quienes obtenían los mejores puestos en la sociedad y a los que el estado debía proteger, instruir y dirigir todo su interés. Para él, los «incapaces» de instrucción, eran los indígenas. El estado no debía dedicar recursos para educar a todos indistintamente. Así en 1921 afirmaba:

\footnotetext{
«Las nociones de ciencia que se enseñan en la escuela, son inútiles para el indio que continúa aislado en su medio ambiente; primero porque no las entiende, y luego porque no tienen aplicación a su labor, ni uso en sus relaciones diarias ${ }^{6}$ 》
}

El uso de las tesis evolucionistas se reflejó con claridad en los discursos políticos desde las dos primeras décadas de nuestro siglo. Para Sierra, entonces Ministro de Instrucción Pública, los caracteres biológicos de cada persona eran determinantes de su posición en la sociedad. «Las leyes, afirmaba, deben asegurar las tendencias evolutivas naturales de la sociedad ${ }^{7}$ ».

A fines de 1916, Carranza, quien ejerció el poder revolucionario desde el 26 de marzo de 1913, fecha del Plan de Guadalupe, hasta mayo de 1917, en que se convierte en Presidente de la República, levantó las banderas del constitucionalismo, hecho que sin duda representó una nueva fase ideológica de la Revolución. Entre los diputados del Congreso Constituyente predominaba el pensamiento liberal, por lo que los planteamientos anarquistas y socialistas están ausentes en los debates del mismo y no se manifiestan en la Constitución de 1917, en la falta de peticiones de los obreros y de los campesinos. A pesar de ello, se considera que la Constitución Mexicana de 1917 fue el mayor logro de la lucha revolucionaria ${ }^{8}$. La lucha revolucionaria,

\footnotetext{
4 ZEA, L., (1968), El positivismo en México: Nacimiento, apogeo y decadencia, FCE, México. Citado en MORENO DE LOS ARCOS, R. (1986), p. 148

5 RUIZ, G.R., (1987), El positivismo mexicano: Introducción del darwinismo en México, UNAM, Serie Posgrado. pp. 147-148.

6 RABASA, E, (1921), La Evolución Histórica de México, Ed. Frente Cultural, México, p.326.

7 SIERRA, J., (1948), Obras completas. Programa de la libertad, México, Tomo IV, p. 238.

8 Roman, Richard, (1976), Ideología y clase en la Revolución Mexicana. La Convención y el Congreso Constituyente, México, SEP. Citado en MORENO DE LOS ARCOS, R. (1986), op. cit. p. 146.
} 
con el triunfo final del liberalismo, cambió el rumbo político de México, hacia la formación de un nuevo modelo de estado liberal, democrático y burgués con orientación corporativista. A pesar de que la ideología y los planteamientos de los grupos más avanzados no llegaron a fraguar, el país resultó después del proceso revolucionario, más unificado, un poco más democratizado, pero sobre todo más nacionalista.

\section{PRoblemática de SALUd EN El MÉXico POSREVOluCionario.}

Es importante señalar que frente a los problemas de salud pública existentes ya desde la segunda década posterior a la Revolución Mexicana (1910), el Estado mantiene una preocupación permanente por legislar en torno a las relaciones matrimoniales, con la finalidad de no perpetuar daños físicos, derivados de sífilis, tuberculosis y otras enfermedades que se consideraban contagiosas o hereditarias, como el caso del alcoholismo persistente. Así, en 1917, el entonces encargado del poder ejecutivo de la nación Venustiano Carranza, propone al Congreso Constituyente la aprobación de la Ley sobre Relaciones Familiares, dadas las numerosas ausencias presentes en el Código Civil vigente al respecto y porque la reforma completa de ese Código implicaba un proceso laborioso y lento.

En la exposición de motivos de la Ley sobre relaciones familiares se observa el empleo de conceptos darwinianos de manera adecuada, y se señala adémás una serie de factores sociales que expresan la urgencia y conveniencia de reformar la legislación acerca de la sociedad mexicana por medio del establecimiento de leyes acordes con el estado de conocimiento vigente:

«... sobre bases más racionales y justas, que eleven a los consortes a la alta misión que la sociedad y la naturaleza ponen a su cargo, de propagar la especie y fundar la familia;

... que las trascendentales reformas políticas llevadas a cabo por la Revolución, no pueden implantarse debidamente sin las consiguientes reformas a todas las demás instituciones sociales, y muy especialmente a las familiares... lo que hace indispensable reglamentar el matrimonio de tal manera, que aseguren los intereses de la especie y los de los mismos cónyuges...

...Que asimismo es necesario, en interés de la especie, aumentar la edad requerida para contraer matrimonio, (esta ley dispone que las mujeres pueden contraer matrimonio a partir de los 14 años y los hombres al cumplir 16) a fin de que los cónyuges sean lo suficientemente aptos para llenar las funciones fisiológicas y morales que les están encomendadas y por la misma causa, conviene también incapacitar legalmente a los incapacitados ya por la naturaleza para las funciones matrimoniales, es decir a los que padezcan de impotencia física incurable, a los enfermos de sífilis, tuberculosis o cualquiera otra enfermedad crónica e incurable, que sea además contagiosa o hereditaria, así como a los ebrios habituales, pues todos los que se encuentran en los casos mencionados dejan a sus descendientes herencias patológicas que los hacen débiles e incapaces de un trabajo eficiente tanto en el orden físico como el intelectual, y transmiten a su vez a las generaciones posteriores su misma debilidad, re- 


\title{
LA INFLUENCIA DE LA SOCIEDAD EUGÉNICA MEXICANA EN LA EDUCACIÓN
}

\begin{abstract}
dundando todo ello en perjuicio de la patria, cuyo vigor depende de la fuerza de sus hijos y en perjuicio también de la misma especie, que, para perfeccionarse, necesita que a la selección natural se añada una cuerda y prudente selección artificial encaminada a orientar y mitigar los rigores de aquélla;...»9
\end{abstract}

El capítulo I de la señalada ley, en su artículo IV, establece que debe presentarse ante el juez del estado civil además de la solicitud matrimonial que debe ser firmada por dos testigos mayores de edad (la mayoría de edad se obtenía en México en ese tiempo a los 21 años), que avalan que no existe impedimento legal para contraer matrimonio, la constancia médica de salud, expedida por dos o más médicos titulados, es decir el Certificado Médico que comprueba que los contrayentes no tienen alguna de las enfermedades que menciona la ley, ni defecto físico que los inhabilite para unirse en matrimonio ${ }^{10}$. Esta disposición era voluntaria y existe desde el decreto del 3 de agosto de 1910; la obligatoriedad del Certificado prenupcial no se encuentra hasta el Código Civil de 1928.

\section{FORTALECIMIENTO DEL NACIONALISMO E INDIGENISMO EN MÉXICO.}

Uno de los intelectuales más interesantes, que impulsó el nacionalismo mexicano desde los inicios del período revolucionario, fue el antropólogo Manuel Gamio ${ }^{11}$, a quien por su formación y producción de conocimiento en el terreno de la arqueología y antropología se ha ubicado como una de las figuras más relevantes. Gamio es considerado en la historia de la antropología americana un innovador desde el punto de vista de la metodología que empleaba, ya que entonces sólo se utilizaba el empirismo, incluso en los trabajos de los científicos mexicanos más destacados.

La etapa fundamental en la formación de Manuel Gamio se relacionó con su cercanía con grandes antropólogos extranjeros que alrededor de 1910 trabajaron en Mé-

9 Ley sobre relaciones familiares, Expedida por el Primer Jefe del Ejército Constitucionalista, Don Venustiano Carranza, el 9 de abril de 1917 y publicada en el Diario Oficial del 14 de dicho mes al 11 de mayo de 1917, en que entra en vigor. Ediciones Andrade,S.A. México, Reimpresión, 2a. Edición 1964. pp. 1-4. Esta ley fue derogada por el artículo 9 transitorio del Código Civil del 30 de agosto de 1928, mismo que tuvo vigencia a partir del primero de octubre de 1932, por decreto presidencial publicado en el Diario Oficial de la Federación del 1 de septiembre de 1932, p. 3-4.

10 Ibid., p. 10-11

11 Se reseña la trascendencia de este personaje ya que a lo largo de su vida profesional manifestó un interés especial por los problemas demográficos -salud, densutrición, calidad de vida- de México, la composición de la población desde el punto de vista racial, y porque además fue un asiduo participante en la revista Eugenesia, órgano de la Sociedad Eugénica Mexicana en los años cuarenta, y participó en diversos cursos que organizó la Sociedad Eugénica Mexicana. Por otra parte, es evidente que Gamio tuvo una sólida formación biológica que se expresa claramente en sus publicaciones por el adecuado empleo de los conceptos evolutivos darwinistas. 
xico, y con la fundación de la Escuela Internacional de Arqueología y Etnografía Americanas. Discípulo de Franz Boas, antropólogo prusiano, reconocido como el maestro de los primeros antropólogos estadounidenses, mexicanos y de algunos otros paises latinoamericanos, y de su colega norteamericana Zelia Nuttall, quien también trabajaba en México, comparten su interés por la cultura prehispánica. Ambos expresan, desde 1901, su inquietud por la enseñanza, la investigación y la formación de la Escuela Mexicana de Antropología. Aguirre Beltrán en su análisis acerca del desarrollo de la antropología mexicana señala: «En el calendario de actividades de Boas la enseñanza y la investigación antropológica en México figuran como contenido de propósito. En 1909 escribe a Nuttall para pedirle que elija entre los mexicanos aficionados a las antigüedades un candidato con inteligencia y deseos de recibir enseñanza profesional en antropología. Zelia Nuttall, con muy buen ojo, propone a Manuel Gamio, y usa sus buenos oficios cerca del Subsecretario de Educación, Ezequiel Chávez, para conseguirle una beca a Gamio quien se embarca en el Puerto de Veracruz rumbo a la Universidad de Columbia, el 5 de noviembre de $1909^{12}$ ».

La postura ideológica y el compromiso social de Gamio con las causas de la revolución se encuentran, desde 1907, en sus publicaciones como secretario de redacción -puesto que ocupó para complementar los raquíticos ingresos que recibía como ayudante del Museo Nacional- de la revista Modern Mexico que se editaba en Nueva York. Gran parte de sus artículos publicados en esa revista, que básicamente se dedicaba a difusión de atractivos turísticos mexicanos, los dedica al análisis de la problemática social, con especial énfasis en el sector indígena y en las cualidades biológicas del mismo, labor que jamás abandonó en su vida, además de su enorme obra en su campo de investigación: la antropología ${ }^{13}$.

\section{NACIONALISMO E IMPULSO DE LA EUGENESIA}

El Estado Revolucionario anticlerical, con bases materialistas, hizo que el México posrevolucionario fuese cada vez más receptivo a los nuevos desarrollos, tanto en el ámbito de las ciencias como en los aspectos sociales. Las ideas evolucionistas eran familiares, muchos naturalistas mexicanos, como Alfonso L. Herrera entre otros, eran evolucionistas convencidos y materialistas, y consideraban que la ciencia podía impulsar la suerte de la humanidad. A diferencia de Argentina, en la que la eugenesia se

12 AGUIRRE Beltrán, Gonzalo, (1983), Lenguas Vernáculas, su uso y desuso en la enseñanza: la experiencia de México, Ediciones de la Casa Chata, SEP, México, pp. 137, 144-145.

13 Gran parte de los detalles de la vida de Gamio y su relación con los antropólogos extranjeros que vivieron en México en los albores de la Revolución, se encierran en la obra de su nieta GONZÁLEZ GAMIO, Ángeles, (1987), Manuel Gamio: una lucha sin final, UNAM, México. p. 25-38. Contiene además un amplio apéndice documental proveniente de su archivo personal. 


\section{LA INFLUENCIA DE LA SOCIEDAD EUGÉNICA MEXICANA EN LA EDUCACIÓN}

instrumenta a partir de los problemas sociales derivados de la inmigración, la sociedad mexicana no se encontraba constituída por inmigrantes, sino fundamentalmente por indios y mestizos. Los viejos debates acerca de la falta de una real integración de los indios en la vida nacional y el problema de poder garantizar la salud de los pobres, condujeron a las ideas del mejoramiento racial y a convergir con la doctrina eugenésica.

En el México de 1910, se publicó el folleto denominado Higiene de la especie: Breves consideraciones sobre la stirpicultura humana, de Francisco Hernández, y un año después, el primer artículo referente al uso de la eugenesia para el mejoramiento racial, a partir de los planteamientos «feministas» del eugenista inglés Caleb Saleeby, que refiere la eugenesia como protección a la mujer frente a las enfermedades venéreas y otros daños relacionados con la salud reproductiva ${ }^{14}$.

Los debates en torno a la eugenesia se incorporan al ámbito médico-social en los años veinte; la adhesión a los programas eugenésicos de salud pública por parte del creciente círculo socialista, no es exclusivo de México y surge con la intención de garantizar y proteger derechos como la salud y la educación.

En 1921, el $1^{\text {er }}$ Congreso Mexicano de Niños, impulsó las banderas de la eugenesia, la herencia y la orientación de la reproducción con fines de mejoramiento racial. El diputado constituyente y Ex-ministro de Instrucción Pública, Ing. Félix Palaviccini, entonces director del periódico El Universal, organizador, presidente del evento e impulsor y posteriormente miembro de la Sociedad Eugénica Mexicana (SEM), propuso la esterilización eugénica de los criminales. Algunos precursores eugenistas radicales la aceptaron y finalmente la propuesta se aprobó por un estrecho margen de siete votos ${ }^{15}$, aunque no tuvo repercusión ni en la práctica ni en lo legal.

La concepción dominante en ese tiempo en México era que las clases media y alta controlaban su reproducción a través de los programas vigentes; pero la clase "menos deseable" o baja no lo hacía; ésto, desde el punto de vista de los eugenistas que incidían directamente en los programas de salud pública, era la causa de la degeneración de la raza mexicana ${ }^{16}$.

En el período posrevolucionario se impulsó la completa separación iglesia-estado, la ideología oficial era profundamente anticlerical, se legaliza el divorcio y se establece la obligatoriedad de la educación básica laica.

En uno de los estados anticlericales más radical, Veracruz, se realizó una gran actividad a iniciativa del Coronel Adalberto Tejeda gobernador del mismo durante dos períodos no consecutivos (1920-23 y 1928-32), quien compartía la preocupación de muchos

14 SAAVEDRA, Alfredo, (1911), «Lo eugénico anunciado por primera vez en México». Acción Médica, reimpresión de 1956, pp. 16-17.

15 NisOT, M.T., (1927), La question eugénique dans les divers pays, Bruselas, Faile, p. 357.

16 HERNÁNDEZ MEJÍA, Agustín, (1933), «Ley de Eugenesia e higiene mental de Veracruz», Eugenesia, 23, 10 de marzo, pp. 3-6. 


\section{LAURA SUÁREZ Y LÓPEZ GUAZO}

pensadores de los años treinta por el problema racial y la posibilidad de su mejoramiento. La amplia obra de «profilaxis social» que instrumentó incluía eliminar el fanatismo religioso, para lo cual cerró la mayor parte de los templos del Estado, algunos los convirtió en escuelas y oficinas públicas, cerró la catedral de la capital desde inicios de 1930, —que no se abrió hasta 1937 - redujo el número de sacerdotes, impulsó la edición de publicaciones contra el clero, como el diario La Sotana, órgano difusor de las ideas de la Liga Comunista Anticlerical, y financió la presentación de obras teatrales como El fanatismo derrotado, y otra en que se relata el atentado de que fue objeto en agosto de 1931 por parte de un seminarista veracruzano, manipulado por el clero católico del estado, del que salió ileso el gobernador; esta obra de teatro, que tuvo gran apoyo económico estatal se titulaba Un atentado criminal $^{17}$, y se relacionaba también con el reciente asesinato por parte del clero del presidente electo Alvaro Obregón.

Otra acción en pro del mejoramiento racial fue la imposición en julio de 1932 de una ley que prohibía el establecimiento de cantinas, tabernas y piqueras, así como la venta de bebidas embriagantes. Tejeda consideraba «notoriamente inmoral que las administraciones públicas aumenten sus ingresos a costa de los vicios que dañan al individuo y a la raza». En comunicaciones con los dos presidentes que gobernaron México durante la gestión de Tejeda, explicó primero al presidente Portes Gil y posteriormente a Pascual Ortiz Rubio, que era imprescindible llevar a cabo «...una ac-

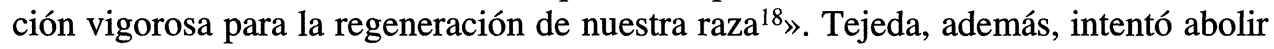
la prostitución «comercial» y para ello clausura:

\footnotetext{
«... las casas destinadas a tal comercio y liberar a esas mujeres del estigma vergonzoso de que las ha hecho víctimas el actual sistema social [...] Pero esa ley no ha nacido sólo de un motivo sentimental, pues se funda en principios racionales y científicos, sin que este Gobierno haya descuidado promover [...] la dignificación moral y la liberación social de la mujer veracruzana ${ }^{19}$ »
}

Finalmente, en julio de 1932, este gobernador de Veracruz, Adalberto Tejeda, uno de los últimos caudillos de la revolución, autoriza la única Ley sobre eugenesia e higiene mental. Para él los avances de la ciencia positivista, el éxito que la genética y la biología habían tenido en la agricultura y ganadería, debía aplicarse a la «raza humana». Para Tejeda su responsabilidad como político era promover el mejora-

\footnotetext{
17 FALCÓN, Romana y GARCÍA, Soledad, (1986), La semilla en el surco: Adalberto Tejeda y el radicalismo en Veracruz, 1883-1960, El Colegio de México y Gobierno del Estado de Veracruz, pp. 263-265.

18 TEJEDA, Adalberto, (1932), Memoria de las labores del Gobierno Constitucional del Estado de Veracruz-Llave durante el cuatrienio 1928-1932, Xalapa, Talleres tipográficos del Gobierno del Estado, pp. 133-134.

19 Ibid., pp. 128-130.
} 


\section{LA INFLUENCIA DE LA SOCIEDAD EUGÉNICA MEXICANA EN LA EDUCACIÓN}

miento físico y mental de los veracruzanos y financiar las investigaciones científicas necesarias para lograr dicha empresa:

\footnotetext{
«Sin exagerar, puede asegurarse que hasta aquí, estos cuidados se han relegado al olvido, pudiendo observarse como sin discernimiento alguno, se reúnen parejas de sifilíticos, de individuos tuberculosos, de alcohólicos inveterados, de personas con defectos mentales, de viciosos y criminales, etc. que sin taxativa alguna van prolongándose en sus descendencias a través de las edades, y legándoles sus miserias fisiológicas. Y estos nuevos grupos de individuos defectuosos, a su vez se levantan ante la humanidad como obstáculo infranqueable para el progreso y mejoramiento social...

Felizmente los trabajos científicos que con verdadero éxito se vienen desarrollando en el campo de la biología, nos han descubierto nuevos horizontes ... en lo que toca al concepto y resolución de los problemas sociales como la criminología, prostitución, alcoholismo, pauperismos y otros que antes pensábase eran debidos en su totalidad a falta de oportunidades, trabajo, educación y otras circunstancias distintas y ajenas al individuo en sí ...

Estas razones hicieron que fuera aprobado el proyecto de ley creando la Sección de Eugenesia e Higiene Mental, que se ocupará del estudio de nuestro medio, de las enfermedades y defectos físicos del organismo humano..

No escapan a la comprensión de este ejecutivo a mi cargo, las gigantescas dimensiones de esta empresa y las enormes dificultades que la misma envuelve, pero se ha propuesto arrojar la semilla en el surco, con la esperanza de que el vigor revolucionario la haga fructificar ${ }^{20}$ »
}

Su rígida concepción de la responsabilidad del gobernante le llevó a promover la «Ley de eugenesia e higiene mental 352», única relativa a la esterilización de criminales existente en México. Unos meses después los enfrentamientos entre radicales y conservadores, en lucha por la tenencia de la tierra en ese Estado, se adueñan del escenario político, por lo que la ley de esterilización queda relegada ${ }^{21}$.

La Sociedad Mexicana de Puericultura se funda en 1929, en la Ciudad de México, con una sección especial de eugenesia dedicada específicamente a la herencia, enfermedades relacionadas con la reproducción, sexualidad infantil, educación sexual y control de la natalidad. De dicha sección de eugenesia surgen los primeros promotores de la Sociedad Eugénica Mexicana (SEM), que se crea en octubre de 1931, con 130 miembros, científicos y médicos, cercanos al círculo político en el poder y a las autoridades de salud pública. Algunos biólogos relevantes por sus conocimientos en el campo de la genética humana eran Fernando Ocaranza y José Rulfo, quienes introdujeron la metodología experimental y la genética mendeliana en México entre 1930-4022.

20 Ibid., p. 132. El título de la obra de FALCÓN, Romana y GARCía, Soledad, (1986), responde a esta cita de las Memorias de Adalberto Tejeda.

21 Ibid., p. 133

22 SAAVEDRA, Alfredo, (1967), México en la educación sexual (de 1860 a 1959), México, Costa Amic, p. 34. 


\section{LAURA SUÁREZ Y LÓPEZ GUAZO}

Los límites de la eugenesia y la oposición a la esterilización fueron motivo de debate en la Sociedad Eugenésica a partir de 1933 23; al siguiente año, la nueva legislación Nazi de esterilización con fines eugenésicos se discutió y criticó sólidamente en la «Segunda Semana de la Eugenesia», en la Ciudad de México. Así la esterilización se transformó en un anacronismo en México.

\section{ANTROPOLOGÍA, INDIGENISMO Y EUGENESIA.}

A principios de 1912 Gamio regresa de la Universidad de Columbia, en donde estudió, becado, una maestría en antropología. A partir de 1916, Gamio se involucra cada vez más en la política; publica su famosa obra Forjando Patria, Pro Nacionalismo, en la que presenta una serie de ensayos alrededor de cómo gestar, a partir del naciente estado revolucionario, una patria fuerte y unida con un profundo sentimiento de nacionalidad:

«Toca hoy a los revolucionarios de México empuñar el mazo y ceñir el mandil forjador para hacer que surja del yunque milagroso la nueva patria hecha de hierro y bronce fundidos ${ }^{24}$ »

El notable historiador mexicano Aguirre Beltrán, respecto a esta etapa y con relación a la postura y el compromiso político de Gamio señala:

\footnotetext{
«Los años que siguen a la fundación de la Escuela Internacional [de Arqueología y Etnografías Americanas, fundada por Boas] son tiempos arduos en que los mexicanos desesperadamente buscan definir su identidad; lo hacen con las armas, con las ideas y con la expresión artística o literaria. La revolución mexicana es populista y en gran medida aborrece al intelectual como una reacción violenta contra el europeísmo de la oligarquía positivista a la que derroca; no es, pues, extraño que sean los hombres doctos los más renuentes a sumarse al movimiento social. ...Como notable excepción, Gamio es de los hombres pensantes que primero se afilian al nacionalismo revolucionario y a las reivindicaciones agrarias que agita Emiliano Zapata en el estado sureño de Morelos; Zapata, líder campesino de los indios y peones irredentos, tiene entre la gente decente de la ciudad capital la reputación execrable que se asigna al asesino, al bandido inmisericorde; la prensa periódica le llama el Atila del Sur. Gamio comete la audacia de exaltarlo, de defenderlo, aún más de calificar de indianismo el pronunciamiento del dirigente de los hombres rústicos del campo ${ }^{25}$ »
}

Este enorme impulso a la ideología nacionalista a partir de los años veinte se manifestó también con la inquietud y anhelo por establecer el concepto de «mezcla ra-

23 OCARANZA, Fernando, (1933), «Límites de la Eugenesia», Eugenesia, 2, pp. 27- 29.

24 GAMIO, Manuel, (1916), Forjando Patria, Porrúa Hermanos, México, p. 5.

25 AGUIRRE BELTRÁN, Gonzalo, (1983) Lenguas Vernáculas, op. cit. p. 61. 


\section{LA INFLUENCIA DE LA SOCIEDAD EUGÉNICA MEXICANA EN LA EDUCACIÓN}

cial constructiva», como reflejo de la identidad racial del mexicano, la misma que se expresaba ya desde la década anterior; entre otros aspectos, en el punto de vista promovido por la obra La raza cósmica, de José Vasconcelos, uno de los jóvenes intelectuales que participaron con las armas en el movimiento revolucionario, y que fundaron el círculo intelectual denominado «Ateneo de la Juventud» en 1909. Esta institución desarrolló una intensa actividad cultural, aunque a finales de su existencia duró hasta 1914- por la enorme actividad política desatada en el país, sólo tenía cuatro miembros activos: Vasconcelos, quien posteriormente fuera Rector de la Universidad Nacional y Secretario de Educación, Pedro Hernríquez Ureña, escritor dominicano, el Maestro Antonio Caso, filósofo y sociólogo y Alfonso Reyes, escritor mexicano. Esta organización cultural promovió la ruptura con la ciencia positiva oficial y su conservadora ideología durante el porfiriato, la misma que había impulsado Gabino Barreda (fundador de la Escuela Nacional Preparatoria), alumno de Augusto Comte, y Justo Sierra, Ministro de Educación durante la dictadura de Díaz.

Uno de los mayores logros del nuevo nacionalismo revolucionario fue el impulso que se le otorgó a los estudios de la población indígena. En 1918, el «Programa de la Dirección de Antropología para el estudio y mejoramiento de las poblaciones regionales de la República», fue presentado por Manuel Gamio, quien fue el titular de la Dirección de Estudios Arqueológicos y Etnográficos de esa institución de 1917 a 1925. De dicho programa destaca Gamio:

\footnotetext{
«...Hemos insistido e insistiremos siempre en la necesidad que hay de investigar las características, las aspiraciones y las necesidades de nuestra población, principalmente de la indígena que es la menos conocida, de acuerdo con una apreciación integral: sociedad, cultura, educativa y antropológicamente en vez de hacerlo desde puntos de vista aislados y unilaterales... ${ }^{26}$ »
}

Es de señalar que uno de los aspectos más interesantes de la metodología de estudio de Gamio, por lo que se le considera innovador en la antropología mexicana, es su marcada tendencia por la interdisciplina, tanto en sus estudios más técnicos -arqueológicos o etnográficos - como en cuanto al abordar problemas poblacionales que se manifiestan claramente en múltiples programas de investigación que impulsó en los diversos cargos públicos que obtuvo.

Siendo Rector de la Universidad Nacional de México José Vasconcelos, en la etapa de Alvaro Obregón, fue designado por éste para encabezar la Secretaría de Educación en la que impulsa:

26 GAMIO, M., (1918) «Programa de la Dirección de Estudios Arqueológicos y Etnográficos», México. Citado en TORRE VILlAR, Ernesto de la y otros, (1984), Historia Documental de México, Tomo II, UNAM, México, p. 614. 


\begin{abstract}
«...La creación de escuelas especiales de indios en todas las regiones pobladas de indígenas y en las cuales se enseñara el castellano con rudimentos de higiene y economía, lecciones de cultivo y de aplicación de máquinas a la agricultura. De esta suerte se logrará que sea más eficaz el trabajo indígena, lo que motivará aumento de jornales y una mayor posibilidad de que la raza se eleve rápidamente. ...Las escuelas rurales se extenderán por todo el país y representarán un grado más que las escuelas indígenas... Cuando los fondos del estado no basten para fundar verdaderas escuelas, la Secretaría mandará maestros ambulantes que recorran las rancherías predicando la buena nueva de la regeneración por el trabajo, la pericia y la virtud...27»
\end{abstract}

Posteriormente, la política indigenista en la época de Plutarco Elías Calles fue encabezada por Moisés Sáenz, que como responsable de la Secretaría de Educación creó la Casa del Estudiante Indígena, el Internado Indígena e inició las Misiones Culturales. Sáenz fue posteriormente director del Instituto Indigenista Interamericano, hasta su muerte en 1941, en que le sucedió Manuel Gamio desde 1942 hasta su muerte en julio de 1960. Este carácter nacionalista se expresó también con el surgimiento del movimiento eugénico, que nunca antes había sido tan sólido en nuestro país, hasta los años treinta. La fundación de la Sociedad Eugénica Mexicana en 1932 coincide con una marcada intensificación del nacionalismo, y la emergencia de estructuras de organización de los trabajadores; la fundación en el inicio de los treinta del Partido Nacional Revolucionario (PNR) en la época de Calles, para cambiar su denominación en 1938 a la de Partido de la Revolución Mexicana (PRM) y que posteriormente sería el Partido Revolucionario Institucional (PRI), partido oficial que desde 1946 se ha mantenido en el poder hasta la fecha.

Los grupos eugenistas centraron su atención en el tema de la consolidación racial y en la concepción de la adaptabilidad de la nación mexicana. Los miembros de la «Sociedad Eugénica Mexicana» discuten la nacionalidad en términos de raza, en el sentido de la heterogeneidad: indios, europeos y mestizos; reconocen la pobreza y marginación en que se encuentran los grupos indígenas y también comparten la idea revolucionaria de las virtudes biológicas de la mezcla racial. Es importante señalar que aunque el término de «vigor híbrido» aún no se acuñaba formalmente en el campo conceptual de la biología, a través del desarrollo de la agronomía y la agricultura tradicional se reconocían las ventajas de la mezcla de variedades con distintas cualidades.

El Dr. Eliseo Ramírez, sostenía que la separación de clases y racial promovida en otros países estaba en contra del ideal eugénico mexicano. Señalaba en los inicios de los años treinta que, aunque algunas mezclas pudiesen reducir las mejores cualidades de los ancestros, también esa hibridación podía conducir a excelentes resultados, como lo había demostrado fehacientemente el genetista ruso Nicolay Ivanovich Vavilov ${ }^{28}$.

27 Parra, Manuel Germán. Citado en Torre Villar, E. de la y otros, (1984), Tomo II, p. 614.

28 RAMíREZ, Eliseo, (1933) «Discurso», Eugenesia, 2, pp.19-22 


\section{LA INFLUENCIA DE LA SOCIEDAD EUGÉNICA MEXICANA EN LA EDUCACIÓN}

El editorial de la Revista Eugenesia de abril de 1940, -revista dirigida por el Dr. Alfredo Saavedra ${ }^{29}$, secretario perpetuo de la SEM-, señala que el estado no puede seguir empleando métodos paliativos con la pretensión de resolver de manera integral el problema de la infancia en México, con su desnutrición y sus taras mentales, que finalmente la gran mayoría representaban los futuros delincuentes profesionales.

«Mientras el estado no procure ir a la causa primera para resolver el problema de la natalidad seleccionada, combatir los factores hereditarios, las enfermedades venéreas, las toxicomanías y se substraigan los deficientes mentales, no podremos tener una raza saludablemente fuerte en el sentido exacto de la palabra. ...no basta con dar de comer al hambriento, ni vestir al desnudo, ni enseñar al que no sabe (o no puede saber), es preciso despertar un concepto racional de responsabilidad ante la descendencia. Hasta entonces la protección integral de la infancia se resolverá científicamente, ...ya que cada niño representa un capital útil a la sociedad. ...La Higiene mental deriva en gran parte de la Higiene racial ${ }^{30}$ »

Otro eugenista significativo fue el Ingeniero Alfredo Valle R., miembro de la Sociedad Eugénica Mexicana desde mayo de 1932, ingeniero agrónomo e hidráulico, egresado de la Escuela Nacional de Agricultura, director de la misma y secretario y profesor de Ciencias Químicas de la Universidad Nacional Autónoma de México. La SEM publicó en abril de 1940 su trabajo titulado «La Población Mexicana y la Eugenesia ${ }^{31} \gg$ y una semblanza de su obra, en homenaje a su reciente fallecimiento ocurrido el 4 de abril de 1940.

En su artículo, Alfredo del Valle destaca la importancia que los gobiernos revolucionarios habían otorgado en el país al «amor hacia el indio», poniendo énfasis, particularmente, en el gobierno vigente en ese momento, el de Lázaro Cárdenas, quien además impulsó de manera contundente el campo mexicano a través de la propiedad comunal y el régimen cooperativo. A diferencia de su antecesor - Plutarco Elías Calles - promovió la organización del sector obrero, constituyéndose la Confedera-

29 El Sr. Dr. Don Alfredo M. Saavedra, uno de los principales eugenistas ortodoxos mexicanos, nació en México en 1893, fue médico cirujano por la Universidad de México y maestro de la misma. Publicó numerosos artículos en las revistas mexicanas: Medicina, Pasteur, Gaceta Médica de México y Eugenesia (Organo de difusión de la Sociedad Eugénica Mexicana, la misma que fundó en 1931 y de la que fue secretario perpetuo). Del contenido de sus publicaciones destaca la importancia que para él tenía la labor de las trabajadoras sociales y de las enfermeras como difusoras de los problemas de salud pública en su época. Algunas de sus obras más relevantes son: Eugenesia y Medicina Social (1934); Apuntes de enfermería (1938); Nociones de Biología (1939); Una lección de trabajo social (1945); Manual de Trabajo Social (1958); Ludoterapia (1965); Un siglo de lucha antivenérea: México en la educación sexual (1967); Historia de la puericultura (1968) y Servir, principios de trabajo social (1970). Murió en la ciudad de México en 1973.

30 «Editorial» (1940), Eugenesia, Tomo I, Núm. 6, pp. 1-2.

31 DEL VAlle R., Alfredo, (1940), «La Población Mexicana y la Eugenesia», Eugenesia, Tomo I, № 6, pp. 11-14. 
ción de Trabajadores de México, organizó sólidos programas "indigenistas" e impulsó la educación con la creación del Instituto Politécnico Nacional, dependiente de la Secretaría de Educación Pública.

A pesar de los esfuerzos del Presidente Cárdenas, afirmaba Del Valle, el indio sigue en su miseria y su aislamiento, en su atraso y el abandono más grande, lo que le colocaba en un índice de mortalidad alarmante. Del Valle señala los datos poblacionales de mortalidad en México de acuerdo con los datos del censo de 1931, publicados en México en Cifras, señalando que si se considerara sólo a la población indígena, las cifras de mortalidad serían «horrorizantes»:

\footnotetext{
«La mortalidad del país es una de las más altas y el coeficiente por millar de habitantes llega al 25.9 para el año de 1931... sólo le aventaja Egipto que alcanza 26.8, siendo el Canadá el de menor mortalidad con 9.9. Este dato explica el porqué de nuestro lento crecimiento demográfico, no obstante el también elevado coeficiente de natalidad, que llega a 43.3 por millar de habitantes ${ }^{32}$ »
}

Esta afirmación de Del Valle, concuerda con la situación general del país en cuanto a la marcada baja densidad poblacional, 7 habitantes por $\mathrm{Km}^{2}$ en los años treinta; la intención de muchos eugenistas notables, quienes también coincidían con el grupo de los «científicos» de la etapa de Díaz, era repoblar nuestro país a partir de la inmigración europea, dando «preferencia a los españoles por su demostrada capacidad de adaptabilidad al clima mexicano».

\section{EUGENESIA, EDUCACIÓN Y MEDICINA SOCIAL.}

Alfonso Herrera, en su obra Biología y Plasmogenia ${ }^{33}$, presenta un esbozo de las aportaciones a la biología mexicana durante un siglo -1821 a 1921—, la que divide en dos períodos, el pre-revolucionario de 1821 a 1909 y el posrevolucionario de 1910 a 1921. En este trabajo Herrera afirma que era imposible que se formaran abundantes biólogos. La falta de preparación de jóvenes en el período pre-revolucionario, para que posteriormente fuesen naturalistas y después biólogos, fue de funestas consecuencias $^{34}$.

Los primeros cursos de biología en el México Pre-revolucionario se iniciaron en la Escuela Normal para Maestros, cuyo Director en 1902, el profesor Enrique C. Rébsamen, dio a Alfonso Herrera en julio de ese año el nombramiento -inmerecido

\footnotetext{
32 Ibid., p. 12.

33 Herrera, Alfonso L., (1924), «La Biología en México durante un siglo», Biología y Plasmogenia, 3a. Ed. corregida y aumentada, Herrero Hermanos, sucesores, eds, México pp. 488-502.

34 Idem.
} 
según este último- de profesor de Biología, después de haber enseñado en la misma escuela, durante muchos años, Historia Natural. Pero después de 1906, afirma Herrera, el gobierno eliminó el año escolar en que se enseñaba «la biología además de otras materias que parecieron peligrosas para la juventud y las creencias ${ }^{35}$ ».

En el período Revolucionario que reseña Herrera (1910-1924), el ingeniero Félix Palaviccini, Ministro de Instrucción Pública, nombra a Herrera en septiembre de 1914 director interino del Museo de Historia Natural. El punto de vista de Palaviccini se refleja en el acuerdo dictado en torno a que los museos existentes, tanto de Historia Natural como otros establecimientos similares, formaran parte de la Secretaría de Fomento, para que tuvieran un enfoque práctico, es decir, que buscaran desarrollar estudios que repercutieran en la industria, en la agricultura, etcétera. Así, los estudios de tipo teórico y la enseñanza de la biología sólo eran responsabilidad de la Universidad. Herrera reseña la fundación del Instituto Médico Nacional en agosto de 1890, cuya función primordial era el estudio de las plantas y animales de importancia desde el punto de vista médico. Aunque, afirma, las modas y los progresos de la terapéutica farmacológica habían desplazado a las especies mexicanas, empleando múltiples rivales que habían llegado al país desde el extranjero ${ }^{36}$. Herrera señala que para 1924 , fecha de la tercera edición de su obra, México, «...no cuenta todavía con recursos suficientes para sostener institutos dedicados a especialidades ${ }^{37}$, y cita el «Diario de los debates», de las Cámaras Colegisladoras del país del mes de diciembre de 1917, en que constan las discusiones y las deficiencias relativas a los establecimientos e instituciones dedicados a las ciencias biológicas, con tan poca relación y coordinación, que algún «establecimiento» mexicano pedía al extranjero ciertas especies, que otro colectaba en nuestro país ${ }^{38}$.

La Sociedad Mexicana de Puericultura editó un órgano de difusión de sus trabajos denominado Revista Mexicana de Puericultura, que festejó su segundo aniversario en noviembre de 1932, siendo en ese tiempo su director el Dr. Anastasio Vergara. Esta publicación contaba en ese año con trece Secciones: la de eugenesia y la sección de higiene prenatal; la de higiene posnatal y alimentación infantil; pediatría, higiene pre-escolar, higiene escolar, higiene y previsión social, legislación infantil, bioestadística, oftalmología, ortopedia, otorrino-laringología y laboratorio. La sección de eugenesia de la Sociedad Mexicana de Puericultura estaba en 1932 a cargo de médicos eminentes, miembros de la SEM, por ejemplo los médicos Rafael Carrillo, Salvador Bermúdez y el Dr. Alfredo M. Saavedra, éste último posteriormente Director de la revista Eugenesia, Presidente de la SEM y secretario perpetuo de la misma hasta su muerte, como ya hemos dicho.

\footnotetext{
35 Ibid., p. 497.

36 Idem.

37 Ibid., p. 492

38 Ibid., p. 493.
} 


\section{-LAURA SUÁREZ Y LÓPEZ GUAZO}

Con el fortalecimiento de la Sociedad Eugénica Mexicana, muchos médicos y educadores que centraron su atención en la educación sexual, combinaron esta postura progresista con otras conservadoras como las campañas antialcohol, antifeminismo y antipornografía. Se impulsan los primeros proyectos de control de la natalidad, de difusión de la salud matrimonial, y se apoya de manera considerable, en 1932, el «Proyecto para la educación sexual y la profilaxis de las enfermedades venéreas» como programa obligatorio de educación oficial para todos los niños menores de diez y seis años ${ }^{39}$.

En una publicación de $1931^{40}$, que representaba la «Declaración de principios de la Sociedad Eugénica Mexicana», la Dra Esperanza Peña Monterrubio, con motivo de su reciente fundación señalaba sus funciones primordiales:

\footnotetext{
«la implantación de la ciencia eugénica cuyos ideales son el mejoramiento de la raza humana, bajo bases científicas, morales y sociológicas, teniendo en cuenta que el mejoramiento de la humanidad, en general no debe consistir en un aumento de progresión numérica, es decir en cantidad, sino más bien en calidad. ¿De qué sirve que una población aumente año con año, si tal aumento abarca un porcentaje de seres degenerados, inútiles a la patria, a la Sociedad, y aún a la Familia, como son: los débiles mentales, los idiotas, los heredosifilíticos, los heredo-alcohólicos, etc., de los cuales están llenos nuestros asilos de Beneficencia y otros muchos que no están recluidos por alguna causa, pero que viven entre la sociedad mostrándole sus lacras que llevan como estigma que sus padres les relegaron como herencia fatal? ${ }^{41}$ »
}

Este documento de la SEM contiene una serie de planteamientos tanto de médicos, como de filósofos y sociólogos de los treintas, en torno a la «importancia de promover el mejoramiento racial». Después de señalar los países en que habían establecido programas eugenésicos, y destacar en cada uno sus principales promotores, afirma que es indispensable que México secunde este movimiento internacional, por lo que la orientación de la SEM será estudiar los problemas de la población y orientar campañas, que, puestas en práctica conduzcan al mejoramiento físico, intelectual y moral de la raza. Por ello, señala como primera labor de la SEM:

\footnotetext{
«...la implantación de la EDUCACIÓN SEXUAL en todas las escuelas, para los que ya pasaron la pubertad y los que aún no llegan a esta edad. ...Por medio de una educación sexual adecuada, para los segundos, se les formará una base moral, sólida, desnuda de hipocresías,
}

39 SAAVEDRA, Alfredo, (1967), México en la educación sexual (de 1860 a 1959), México, Costa Amic, pp. 31 y 101

40 PEÑA MONTERRUBio, Esperanza, (compiladora), (1931), Conceptos eugénicos. Nuevas orientaciones. La enseñanza sexual y la religión. Pensamientos de Médicos, Filósofos y Sociólogos Mundiales, México D.F., 52 pp.

41 Ibid., p. 3. 


\section{LA INFLUENCIA DE LA SOCIEDAD EUGÉNICA MEXICANA EN LA EDUCACIÓN}

engaños y prejuicios, para que su vida futura no sea defraudada más tarde como sucede actualmente por la FALTA DE PREPARACIÓN ${ }^{42}$,

Respecto a la importancia de introducir los principios eugénicos en la enseñanza, la Dra. Peña Monterrubio destacaba la orientación que debían seguir los maestros en los programas escolares de educación sexual como un sistema progresivo en sus clases de Historia Natural, que fuera desde la fecundación en las plantas hasta los animales, desde los inferiores hasta los mamíferos, para finalmente estudiar la procreación del hombre. Reitera la importancia que para los padres, maestros y para todos debe encerrar este tipo de educación, ya que, dice, una vez que conozcan la procreación, podrán conocer los peligros que significan, para la salud y la descendencia, las enfermedades que adquieren los jóvenes por su ignorancia y por la explotada idea de que las enfermedades venéreas son "vergonzosas", lo que les conduce a guardar el secreto, mal curándose o no haciéndolo, con perjuicio de su salud y más tarde de su descendencia. Por ello, afirma:

«...debe encauzarse a los jóvenes para que las relaciones sexuales se orienten a la fundación de la familia y no como motivo de placer únicamente sin preocuparles las consecuencias ${ }^{43}$ »

$\mathrm{Al}$ respecto señala Peña el pensamiento del Dr. César Juarros, Director del Departamento de Psiquiatría de la Escuela Central de Anormales de Madrid, quien afirmaba:

\footnotetext{
«Olvídase que el placer es una recompensa, no un derecho, búscase en el salario, elúdese la obligación, obligación sagrada de contribuir a la conservación y mejora de la especie ${ }^{44}$ »
}

Al final de la presentación de esta publicación, la Dra Peña Monterrubio asegura que uno de los primeros pasos de la SEM fue el enviar un proyecto de Educación Sexual y Propaganda antivenérea y antialcohólica a los gobernadores de los Estados de la República; esa propaganda debe alcanzar, afirma, todos los rincones de nuestro país; y respecto al proyecto de educación sexual, está en estudio para establecerlo oficialmente en las escuelas ${ }^{45}$.

El contexto político-social y cultural de nuestro país dio un mayor impulso al uso positivo de la eugenesia; en ésto jugó un papel central la sección de eugenesia de la

\footnotetext{
42 Ibid., p. 4.

43 Ibid., p. 5

44 Idem.

45 Ibid., p. 7. 
Sociedad Mexicana de Puericultura, encabezada por el notable médico eugenista Dr. Rafael Carrillo.

En el primer aniversario de la Sociedad Eugénica Mexicana, celebrado en septiembre de 1932, el entonces presidente y jefe de la sección de eugenesia de la Sociedad Mexicana de Puericultura, el citado Dr. Carrillo, publicó un interesante trabajo titulado «Tres problemas mexicanos de Eugenesia, Etnografía y Etnología, Herencia e Inmigración ${ }^{46}{ }_{»}$. En su introducción al trabajo señala Carrillo:

\footnotetext{
“Aprovechando la circunstancia de que la Sociedad Eugénica Mexicana, ha celebrado su primer aniversario con un éxito muy lisonjero, quiero delinear, aun cuando sea someramente, algunos temas eugenésicos de carácter francamente mexicano y que considerados desde un plano muy general son los fundamentos del mejoramiento de la raza ${ }^{47}$ »
}

Señala que es de todos conocido que entre los siglos XV al XVIII se estableció una corriente emigratoria que vino hacia América, formada especialmente por españoles; que a esta raza se añadieron posteriormente otras muchas, ingleses, franceses, italianos, árabes, sirio-libaneses, judíos, americanos, turcos, lituanos, negros, etc., lo que revela, afirma Carrillo, la infinidad de razas que constituyen la población de la República Mexicana. Presenta una serie de cifras, en que destacan los datos sobre la población de la Nueva España en el siglo XVI que era, sin contar los indios, como sigue: españoles 17,711 , negros 18,569 , mestizos 3,370 y mulatos 1,560 . Y señala que para los años treinta, los mestizos o mexicanos constituían más del $50 \%$ de la población, los indios el $30 \%$, los negros el $1 \%$, los mismos que fundamentalmente procedían de las islas antillanas u oceánicas y el resto de las demás razas mencionadas.

Carrillo consideraba que era indispensable conocer la etnología de esta variedad de grupos, particularmente las constantes físicas -en términos antropométricos-y conocer datos sobre sus caracteres patológicos, inmunidad, evolución, etc. Criticaba también a los etnógrafos de su tiempo por no haber podido establecer el número de razas de «nuestra especie», dadas las dificultades para encontrar los ejemplares «puros» que lo permitieran. A pesar de ello, aseguraba que de manera generalizada los numerosos pueblos que habitaban nuestro país pertenecían a la raza amarilla, representada por el indio; a la raza blanca, europea y a la raza negra ${ }^{48}$.

Para Carrillo, la multitud de tipos existentes en México derivaba del cruzamiento de esas razas entre sí. El primero y principal cruce, por su cantidad, fue el del español con la india, dando lugar a mestizo o mexicano; después, con los diferentes tipos

46 CARrillo, Rafael, (1932), «Tres problemas mexicanos de Eugenesia, Etnografía y Etnología, Herencia e Inmigración», Revista Mexicana de Puericultura. Organo de la Sociedad Mexicana de Puericultura, Tomo III, $\mathrm{N}^{\circ}$ 25, «Sección de Eugenesia», pp. 1-14.

47 Ibid, p. 1.

48 Ibid, pp. 2-3. 


\section{LA INFLUENCIA DE LA SOCIEDAD EUGÉNICA MEXICANA EN LA EDUCACIÓN}

europeos que han inmigrado a nuestro país; a estos grupos debía añadirse el cruce del español con la negra, formando el mulato; de mestizo y española, el castizo, etc. etc. dando lugar esta serie de mezclas al quarterón, quien tiene $1 / 3$ de una raza y $3 / 4$ de otra, y quinterón, que representa el tipo racial que tiene $1 / 5$ de una raza y $4 / 5$ de otra.

Debido a la existencia de tan variado mosaico racial en México, y con la necesidad del eugenista de conocer de qué manera puede orientarse, recomienda el estudio de los caracteres antropométricos que distinguen entre sí a estas razas, estudiar sus funciones biológicas y su mentalidad y distinguir sus aptitudes y sus valores morales, para lo que se necesitaba un amplio estudio etnológico. Carrillo consideraba, además, que desde el punto de vista de la eugenesia era indispensable realizar un estudio acerca de la herencia, concebida de acuerdo con la definición del Dr. Renato Kehl, uno de los más destacados eugenistas brasileños:

\footnotetext{
«La herencia a nuestro entender es la disposición especialísima de la materia viva para conservar íntegramente su constitución específica (forma y función) a través de sucesivas generaciones ${ }^{49}$ 》
}

Es interesante destacar que menciona que no se detendrá en aquellos hechos hipotéticos que corresponden a las denominadas teorías de la herencia, como las de Darwin, Weismann o de los «cromosomos», sino que sólo se referirá a las leyes de Mendel y a las de Galton. Señala diversos ejemplos de cruzas de animales de raza pura y color negro de piel con albinos, y deduce las cualidades de la F1 y F2 en que evidencia un claro conocimiento general acerca de los principios de la herencia mendeliana. A pesar de ello, para la especie humana señala casos de herencia ligada al sexo - formulada por el «Grupo de la Mosca» de Morgan, que considera Carrillo como propuesto por Mendel-y utiliza ejemplos que no son reales:

«Aplicando la ley de Mendel al hombre, se ha observado que ciertos caracteres son trasmitidos sólo por un sexo. Por ejemplo una mujer con ojos claros, de color claro, se une con un hombre de color obscuro, sucederá que los hijos (varones y hembras) tendrán sus ojos de color claro, pero mientras que los hijos tendrán hijos con color de ojos obscuros, las hijas tendrán hijos donde la mitad tendrán ojos claros y la otra mitad ojos de color obscuro.

Igual aplicación puede hacerse respecto a ciertos defectos, dientes supernumerarios, hemofilia, hipospadias, zurdos, etc, donde aparece el carácter dominante ${ }^{50}{ }_{\text {» }}$

Con respecto a la aplicación que podría hacerse de los principios de Mendel a la Eugenesia propone Carrillo una serie de medidas:

\footnotetext{
49 Ibid., p. 4.

50 Ibid., p. 5.
} 
« $1^{\circ} \ldots$ si hay algún dominante en la familia que es indeseable reproducir en ella, entonces es indispensable para un miembro afectado abstenerse de tener hijos.

Pero un miembro no afectado de la misma familia puede casarse con otra persona no afectada sea o no pariente (primo) con inmunidad.

$2^{\circ}$ Los anormales se pueden casar con normales sin huellas de defectos y si su descendencia normal se casa con personas fuertes, entonces el defecto puede desaparecer, pero los matrimonios consanguíneos en tales casos (aún cuando sean normales) deben evitarse.

¿Quién puede traer una cosa limpia de una sucia? El Eugenista.

Por otra parte los varones normales con inmunidad pueden casarse, pero las mujeres normales, que tienen hermanos afectados no deben tener hijos.

Por otra parte, desgraciadamente es un hecho que los nacimientos entre los afectados de debilidad mental, es doble que en los normales. De aquí las medidas preventivas.

La Comisión Real Inglesa, demostró que el porcentaje de nacimientos entre los afectados de debilidad mental, es doble que en los normales. De aquí las medidas preventivas.

Dos faces de eugenésicos se presentan: los positivos y los negativos. Los negativos excluyen a las clases no adaptadas. Se evita la reproducción entre ellas para que puedan ser eliminadas gradualmente ${ }^{51}$ »

Carrillo señala en este amplio artículo que para explicar los aspectos relacionados con la herencia utilizará los planteamientos de Galton. Así, afirma que la teoría de Galton tenía por objeto medir las cualidades de una población valiéndose de cálculos matemáticos, y que se diferenciaba del mendelismo porque éste era experimental y utilizaba sólo casos concretos, los observaba y clasificaba, mientras que la biometría galtoniana medía la frecuencia y extensión de las diferentes clases de variación, y por ser matemática, dice, «...puede abarcar problemas más complexos ${ }^{52}$ ».

Carrillo interpreta la «ley de la regresión filial de Galton», como «la tendencia de aproximar la descendencia a la media general de los progenitores». Y da un ejemplo:

«...se ha observado que los hijos de los grandes hombres, son en general mediocres y que los hombres de gran relieve proçedieron de padres menos notables ${ }^{53}$ ».

Es claro que este planteamiento representa una interpretación adecuada acerca de la concepción de Galton respecto al fenómeno de la regresión filial, quien en un ejemplo respecto a la herencia de la estatura afirma:

"Como los dos Padres contribuyen igualmente, la contribución de cada uno de ellos puede ser solamente un medio de la de los dos juntos; en otras palabras, sólo un medio de la del

$\begin{array}{ll}51 & \text { Ibid., p. } 6 . \\ 52 & \text { Idem. } \\ 53 & \text { Ibid., p. } 7 .\end{array}$ 


\section{LA INFLUENCIA DE LA SOCIEDAD EUGÉNICA MEXICANA EN LA EDUCACIÓN}

Padre-promedio. Por lo tanto la Regresión media de la Estatura Medio-paternal a la Mediofilial debe ser un medio de los dos tercios, o un tercio ${ }^{54}$ »

Carrillo propone que el conocimiento de las razas humanas y de la herencia deben ser el fundamento de un proyecto eugenésico, para impulsar el «Mejoramiento de la Raza Mexicana», y convoca a las autoridades mexicanas de salud, de educación y a todos los círculos intelectuales que se preocupan por nuestra raza, a fundar un Instituto Mexicano Experimental de Eugenesia, similar al Eugenics Record Office de Estados Unidos, o al de Inglaterra, Alemania, Brasil, etc. Propone además que ese Instituto comprenda siete secciones: estudio físico, psíquico y moral constitucional de todo individuo; examen psicopedagógico y criminológico; orientación profesional y psicotécnica; genealogía y pronóstico hereditario; ortogenética, física y corrección de anomalías; medicina del trabajo y nutrición ${ }^{55}$.

Para Rafael Carrillo eran tres los factores que determinaban la conformación etnográfica de nuestra República: la inmigración, las razas y la herencia. Respecto al primer factor, señala que la afirmación de Malthus en cuanto al exceso de población y las condiciones difíciles de lucha por la existencia, además del afán de los europeos en busca de aventuras y riquezas, encontrando en nuestro país inmensas extensiones de terreno despobladas, con elementos naturales en abundancia, favorecieron la inmigración tanto de Europa como de Asia y la seguían promoviendo. El hecho de que los gobiernos no hubieran instrumentado políticas que limitaran dicha inmigración había permitido, dice, el ingreso de millares de individuos, no sólo de diversos caracteres somáticos, sino que entre ellos existían taras morbosas indeseables y caracteres mentales inferiores, lo que había conducido a la formación de una «ensalada de razas con capacidades distintas», que, según él, impedía la unidad nacional equilibrada en el sentido psicológico ${ }^{56}$.

Para Carrillo, México, al igual que Brasil, representaba un gran laboratorio en el que debería elaborarse durante mucho tiempo un gran metabolismo racial, con asimilación de unos y desasimilación de otros, y mediante esa labor completa y lenta que expresa la óptica gradualista de la evolución racial del Dr. Carrillo- «se obtendrá, a pesar de los prejuicios que se infieren a la raza blanca, una nacionalidad mejor caracterizada, un pueblo fuerte y varonil que tal vez podrá compararse con los mejores dotados». Carrillo nuevamente señala su afinidad con el notable eugenista brasileño Renato Kehl, en cuanto que «el cruzamiento dará vigor a las razas, siempre y cuando posean caracteres similares», por ejemplo entre las razas arias, pero no acepta que resulte tal vigor cuando las razas a cruzar tengan caracteres marcadamente dis-

\footnotetext{
54 GaltoN, Francis, (1988) «La herencia natural: Regresión», Francis Galton. Herencia y Eugenesia, Traducción, Introducción y Notas de Raquel Alvarez Peláez, Alianza Editorial, Madrid. p. 146.

55 CARrillo, (1932) p. 8.

56 Ibid., p. 9. 


\title{
LAURA SUÁREZ Y LÓPEZ GUAZO
}

tintos, como entre blancos, negros e indios; sostiene que el mestizaje o fusión de razas se mantiene indefinidamente, «debido a que la raza blanca, siendo como es superior, prevalecerá sobre las inferiores, la negra y la india ${ }^{57}$ ». Dado que se había observado, aparentemente, que el mulato tenía poca resistencia vital y menor fecundidad que las razas puras, tal como se había estudiado, dice este autor, en Jamaica, Java y Carolina del Sur, y con postura lamarckiana indica que en esos casos las dificultades de aclimatación eran las que producían esos fenómenos; y alude al brasileño Renato Kehl, quien sostenía que el cruzamiento entre razas representaba un elemento perturbador de la evolución natural y no constituía un medio de perfeccionamiento étnico ${ }^{58}$. Para Carrillo:

\begin{abstract}
«...los censos revelan que México ocupa uno de los primeros lugares respecto a su índice de natalidad, aunque es cierto también su elevado índice de mortalidad infantil, de tal modo que se compensan ambos factores; por lo que no es una necesidad para México favorecer la inmigración. ...Las amplias campañas por parte del movimiento obrero, la ley del trabajo y el esfuerzo vigoroso de los comerciantes en favor del consumo nacional representa a gritos: México para los mexicanos y mientras mayor sea la lucha por los nacionales para triunfar en la vida más grandes serán también los medios de defensa contra el extranjero. ...Pero si como deseamos los eugenistas mejorar paulatina y progresivamente nuestra raza por medio de la inmigración, es necesario que ésta se efectúe en condiciones óptimas ${ }^{59}$ »
\end{abstract}

Para Carrillo los primeros colonizadores que vinieron del Antiguo Continente estuvieron muy lejos de llenar los requisitos de la eugenesia, entre ellos individuos indeseables por sus cualidades fisiopsíquicas inferiores a los de la población autóctona. Y piensa que, desgraciadamente, este fenómeno se había repetido posteriormente, lo que había incrementado los problemas raciales de nuestro país. Por ello pensaba que el gobierno mexicano debía ser muy estricto en la admisión de extranjeros. El concepto de selección artificial de Carrillo es muy claro:

\footnotetext{
«... si no queremos apartarnos de nuestro ideal [eugénico]..., ...Naturalmente no pensamos hacer nuestra selección entre los individuos eugenésicos superiores; no pretendemos un Marañón, un Shaw, un Mussolini, un Hindenburg o un Edison, pero tampoco aceptamos epilépticos, alcohólicos, débiles mentales o luéticos, sólo queremos para inyectar a los mestizos mexicanos sangre de eugénicos que conforme a la escala de valores ideada por Galton no se alejen ostensiblemente de la media ${ }^{60}$ »
}

\author{
57 Idem. \\ 58 KeHL, citado en CARRILLO, op. cit. p. 19. \\ 59 Ibid., p. 12. \\ 60 Ibid., pp. 12-13.
}




\section{LA INFLUENCIA DE LA SOCIEDAD EUGÉNICA MEXICANA EN LA EDUCACIÓN}

Considera que la inmigración nos permite practicar la «eugenesia positiva», a través de la selección de razas; sostiene que todos los etnólogos admiten que la raza blanca y especialmente la raza nórdica de Europa es la que posee los valores más altos de la escala de Galton, que por tanto el gobierno debe darle preferencia.

Con relación a la «eugenesia negativa», Carrillo sostiene que se debe definir cuáles razas se deben desechar y se cuestiona, respecto al rechazo a la raza amarilla que impulsa la política migratoria de Estados Unidos, por su temor a la predominancia de esa raza sobre la blanca: ¿se deben excluir por el abuso que hacen de los narcóticos o por su fealdad física? $\mathrm{O}$ ¿debemos permitir el cruzamiento con los mestizos mexicanos por el hecho de que algunos etnólogos aceptan el origen asiático de la raza indígena a partir de la raza amarilla y considerarlas como razas afines? Y alude al Boletín Oficial de Salubridad Pública de 1930, que afirmaba, respecto a la inmigración amarilla en América, que el japonés no era un organismo adecuado para los climas cálidos, poniendo como ejemplo el caso brasileño, en que los intentos de colonización japonesa han fracasado por su enorme susceptibilidad al paludismo. Dice que la zona intertropical había causado en esa raza la más alta letalidad conocida.

En relación a la posibilidad de mezclar los mestizos mexicanos con la raza negra, Carrillo cita a Samuel Holmes, quien sostenía que la raza negra era más susceptible a la tuberculosis y otras afecciones pulmonares, pero más resistente a la erisipela, difteria, diabetes, apendicitis y algunas afecciones hepáticas ${ }^{61}$. Por ello, afirma Carrillo, es importante definir cuáles son las razas con las que podemos aplicar la eugenesia positiva, cuáles la negativa y con cuáles más la preventiva. Los gobiernos, piensa, deberían establecer oficinas en los puertos y fronteras con personal adecuado, enterado de los problemas eugénicos:

\footnotetext{
«Las autoridades sanitarias deben considerar el punto de vista de la eugenesia cuando los turistas extranjeros pasan al lado mexicano sólo por algunas horas, tiempo más que suficiente para que dejen una siembra de gonococos o de Schauden o bien engendren un débil mental ${ }^{62}$ »
}

A pesar de la superioridad que le otorga Carrillo a la raza blanca, su postura nacionalista se manifiesta al referirse a las ventajas del mestizaje en México, que dice se refleja en el incremento de la estatura con relación a la raza blanca ancestral, y también en el cruzamiento de las diversos grupos autóctonos:

«¿Debemos seguir la política de los norteamericanos de eliminar a la raza india y de reconcentrar a los indios rojos en las regiones rocosas del N.O?

61 Ibid., p. 13.

62 Ibid., p. 14. 


\begin{abstract}
¿Debemos impedir las uniones sexuales con los tipos de aquella raza, que en sus orígenes dieron testimonio de una civilización más o menos avanzada como los antiguos mexicanos, mixtecas y zapotecas, los mayas entre otros?

... a juzgar por la apreciación de casos particulares, hemos tenido tipos indígenas que bien pueden colocarse en la escala media de Galton y donde algunos de ellos pueden ser considerados como superiores ${ }^{63}$ »
\end{abstract}

En los inicios de nuestro siglo, en general el problema de la población nativa se abordaba con mentalidad discriminatoria, existía el prejuicio de que los pobladores nativos representaban un lastre para lograr los ideales del positivismo —orden, desarrollo económico y progreso-. No se impulsaba ninguna política indigenista, ni siquiera en lo jurídico o formal. Algunos esfuerzos aislados en el aspecto educativo de tipo regional lograron el establecimiento de escuelas indígenas en la Sierra de Chihuahua ${ }^{64}$. Esta concepción de orden y progreso, se pensaba podía modificar el problema demográfico, pero fundamentalmente en lo racial, a partir de transformar la composición étnica con las aportaciones genéticas y culturales a través de la inmigración de la raza blanca.

La mayor parte de los eugenistas mexicanos ortodoxos compartían las ideas de Vasconcelos en torno a las ventajas que para los indios había traído la mezcla con los europeos. Una excepción interesante a esta polémica representa la postura del antropólogo e indigenista Manuel Gamio, quien señalaba las grandes ventajas que para los europeos en México había representado la intensa mezcla con los indios, pues habían adquirido su adaptación al clima y a la geografía, a lo largo de varios siglos, por el severo efecto de la «selección natural ${ }^{65}{ }$. El empleo reiterado de los conceptos darwinistas de «adaptación» y «selección natural» por parte del Dr. Manuel Gamio se hace de manera adecuada. Los utiliza para explicar las diferencias que el estado debía considerar en cuanto a la orientación de los programas sanitarios que implemente. Particularmente respecto a los problemas demográficos - fundamentalmente el elevado índice de mortalidad entre la población indígena-y por ello afirmaba Gamio que no era posible para el gobierno mexicano diseñar un sólo programa de salubridad, dada la diversidad de los grupos que poblaban nuestro país y la diversidad biogeográfica y de climas:

63 Ibid, pp. 14-15.

64 «Ley del Estado de Chihuahua, para Mejoramiento y Cultura de la Raza Tarahumara, del 3 de noviembre de 1906». Otros casos aislados fueron la «Ley de Educación del Estado de México», establecida por Ignacio Ramírez para becar estudiantes indígenas de la escuela normal y en la de Artes y Oficios de Toluca y la «Ley de 1990 del Estado de Chiapas», sobre escuelas especiales para indios. Cfr. ZAVALA, S. y J. Miranda, () «Instituciones indígenas en la colonia», en Métodos y Resultados de la política indigenista en México. INI. Memorias, Vol IV, México, D.F. p. 11.

65 GAMIO, Manuel, (1942), «Algunas consideraciones sobre la Salubridad y la Demografía en México, Eugenesia, Tomo III, No 28, p. 3-8. 


\title{
LA INFLUENCIA DE LA SOCIEDAD EUGÉNICA MEXICANA EN LA EDUCACIÓN
}

\begin{abstract}
«Los grupos aborígenes mexicanos son probablemente los que arrojan más altas cifras de mortalidad y requieren la aplicación de más costosos y amplios programas de salubridad, son en realidad los más saludables puesto que sus ascendientes han vivido en el país desde hace millares de años.

...En efecto virtualmente el indio tiene más defensas naturales que el blanco y el mestizo, y debería desarrollarse mejor y multiplicarse más que ambos, pero tal cosa no sucede así, porque a las ventajas que al indio entrañan la «adaptación» y la «selección», se oponen serios factores, cuya acción no sólo las neutraliza, sino que generalmente las supera; ... estos factores tanto históricos como contemporáneos ... han sido principalmente los del medio social, o sean los de índole económica, cultural y psíquica ${ }^{66_{»}}$
\end{abstract}

Gamio diferencia tres grupos que conforman la población mexicana: grupos aborígenes, grupos de origen europeo y grupos mestizos. Con relación al primer grupo señala diferencias en cuanto a la capacidad torácica, como producto del efecto de la selección y la adaptación. Para Gamio existe una relación directa entre la altitud y el incremento de la capacidad torácica, que se refleja en los descendientes de los aztecas y otros aborígenes que habitan en la altiplanicie mexicana. Destaca las diferencias entre la inmunidad respecto al paludismo de los mayas y otros aborígenes que viven en las zonas bajas del país, en contraste con los europeos, como producto de la adaptación:

\footnotetext{
«Cuando los grupos autóctonos vivan en condiciones de medio social iguales o análogas que las que caracterizan la existencia de la población de origen europeo, su desarrollo físico será incomparablemente mejor que el de éstos y los programas de salubridad que para entonces se elaboren y apliquen tendrán menores requerimientos y les serán más eficaces que a los otros grupos de la población, puesto que gozan de las ventajas innatas originadas en la adaptación y en la selección natural ${ }^{67}$ 》
}

Para Gamio es indispensable que el estado instrumente programas especiales de salubridad, basados en previas y acuciosas investigaciones relacionadas con las condiciones del medio social en que se desarrollan los variados grupos étnicos existentes en nuestro país.

Respecto al segundo punto, grupos de origen europeo que no se han mezclado con los aborígenes, señala que a pesar de que se establecieron desde el siglo XVI en México, hasta la fecha carecen de las naturales defensas biológicas que caracterizan a los indígenas, lo que ha repercutido en la población en general, «y hasta determinan ciertos aspectos desfavorables de nuestra economía... ${ }^{68}$

\footnotetext{
66 Ibid., p. 6.

67 Ibid., p. 6.

68 Ibid., p. 7.
} 
Respecto al tercer punto, los mestizos, Gamio afirma que para que el grupo de origen europeo pueda adaptarse y gozar de las ventajas del grupo autóctono, debiera mezclarse con los aborígenes y en ese sentido debiera orientarse para ese grupo particular la política de salud en México, y afirma:

«...no sólo por su conveniencia políticosocial, sino principalmente por los benéficos resultados biológicos que trae consigo ${ }^{69}{ }^{»}$

En un trabajo dedicado a la educación sexual en México presentado en la Sociedad Eugénica Mexicana, el Dr. Adrián Correa, miembro de la sección de eugenesia de la Sociedad Mexicana de Puericultura ${ }^{70}$, señala que la sociedad mexicana está aferrada a costumbres ancestrales, cargada de prejuicios, de una moral mal orientada, hasta cierto punto intransigente y que posee un nivel intelectual que deja mucho que desear; todos esos factores la llevan a considerar la educación sexual como «inmoral» y dejan al azar y al tiempo dicha educación. Tanto los padres como los maestros y hasta los médicos, afirma, se declaran contrarios a su enseñanza, fundándose en dificultades y prejuicios que consideran invencibles, para desempeñar esta función con los niños y hasta con los adultos. Propone una educación sexual «gradual» y «paulatina» de los niños, de los jóvenes y de los adultos, con el apoyo de pedagogos, médicos, higienistas, abogados, etcétera. Para el Dr. Adrián Correa y muchos miembros de la Sociedad Mexicana de Puericultura, que compartían la preocupación acerca de la importancia de la educación sexual, ésta debía considerarse de manera integral y por tanto incluir el «medio», la «herencia» y el «individuo», ya que considera que son los factores que influyen de manera prioritaria en el desarrollo intelectual:

«Si la herencia psíquica es buena y el medio en que vive el niño es malo intelectualmente, el desarrollo psíquico del niño se detiene. Por el contrario un niño que tenga herencia psíquica mediocre, puede tener un buen desarrollo psíquico si el medio en que vive es intelectual $^{71}$ »

Aunque Correa declara ser un eugenista radical, se puede observar en la cita anterior que su concepción es marcadamente ambientalista y por tanto absolutamente distante a la concepción de Galton, quien despreciaba el efecto de la crianza en el desarrollo de las capacidades intelectuales, para otorgar exclusivo valor a la herencia. Para el Dr. Correa, dado que los inicios de la educación sexual se imparten en el seno

69 Ibid., p. 8.

70 CORREA, Adrián, (1932), «Cómo debe impartirse la educación sexual en nuestro medio», Revista Mexicana de Puericultura, Tomo II, N 17, Sección de Eugenesia, p. 237-246.

71 Ibid., p. 238. 


\section{LA INFLUENCIA DE LA SOCIEDAD EUGÉNICA MEXICANA EN LA EDUCACIÓN}

de la familia y fundamentalmente por parte de la madre, es indispensable que el estado ofrezca educación sexual para los padres en primera instancia, y dado que ésta debe ser una de las bases de la instrucción moral de la vida escolar, el maestro, el pedagogo, debe brindar educación en torno a los aspectos relacionados con la sexualidad y mantener al mismo tiempo en sus discípulos una sana curiosidad, un verdadero espíritu inquisitivo y amor al conocimiento. Pero dado que muchos maestros han descuidado el cultivo de las nociones precisas de biología, psicología, fisiología y sociología, sostiene Correa, indudablemente que, en lo que se les puede preparar para esta misión, nuestros jóvenes tendrán que adquirir esta enseñanza por la lectura, de las personas mayores que no se olvidan de cuando fueron jóvenes y que de sus propias vidas han cosechado el conocimiento y comprensión de estos hechos ${ }^{72}$. Correa consideraba que a los niños se les debía guiar hasta la pubertad, que es cuando debe hacerse verdadera enseñanza de la profilaxis de las enfermedades venéreas. Y que la educación sexual debía adaptarse delicadamente, dependiendo del temperamento individual ${ }^{73}$, por lo que propone impartir un programa de educación sexual teniendo en cuenta los conocimientos de las ciencias naturales, botánica, zoología y biología.

En un trabajo presentado por el Dr. Anastasio Vergara director de la Revista Mexicana de Puericultura y el Dr. Octavio Rojas Avendaño, ambos miembros de la sección de eugenesia de dicha sociedad, ante la Sociedad Eugénica Mexicana en la sesión del 5 de septiembre de $1932^{74}$, se expresa con claridad su conocimiento en torno a los mecanismos de la herencia, al menos respecto a los planteamientos de Weismann, en torno a la separación del germen y del soma. Afirman que el empleo de substancias tóxicas puede afectar, por ejemplo, al riñón, efecto que consideran similar al de un agente infeccioso, pero que de ninguna manera, dicen, se transmite por medio de la herencia biológica:

\footnotetext{
«...sería disparatado considerar que las infecciones se heredaran. Un ejemplo de este absurdo, lo tenemos en la llamada «heredo-sífilis», término erróneo, porque no es la infección la que se hereda, hablando propiamente con criterio biológico, pues es la madre la que infecta a través de la placenta a su hijo, de tal manera que la llamada «heredo-sífilis», debería llamarse con propiedad «Sífilis congénita», pues el treponema viene a instalarse mucho después de que se ha efectuado la fecundación, y no es posible concebir que se herede una infección, sino que son infecciones de madre a hijo.

... de tal modo que éstas [infecciones] no son de tomarse en cuenta directamente como causas del desmejoramiento racial,... ni las infecciones ni las auto-intoxicaciones pueden aceptarse como caracteres adquiridos para que trascendieran en la herencia biológica ${ }^{75}$ 》
}

\footnotetext{
72 Ibid., p. 240-242.

73 Ibid., p. 244.

74 Vergara E, Anastasio, ROJAS AVENDAÑo, Octavio, (1932), «iSon de tomarse en consideración las auto-intoxicaciones, como causa del desmejoramiento racial?», Revista Mexicana de Puericultura, Tomo III, No 24, pp. 449-453.

75 Ibid., p. 450.
} 


\section{LAURA SUÁREZ Y LÓPEZ GUAZO}

Los caracteres adquiridos, para estos autores, se heredan. Es interesante resaltar, que a pesar de que los autores aparentemente manejan con claridad la separación entre germen y soma, de acuerdo con la postura de Weismann, no han eliminado del todo el esquema lamarckista en torno a la herencia de caracteres adquiridos, ya que aunque señalan que las infecciones y auto-intoxicaciones no se pueden considerar como caracteres adquiridos que se transmitan a través de la herencia, dejan implícito el que puede haber otros caracteres adquiridos que sí se expresen en la descendencia, lo que pone en evidencia el retraso en que se encontraban los eugenistas mexicanos tanto en el marco de la situación del evolucionismo como de la genética en los años treinta.

Ya en los años cuarenta, el notable eugenista Del Valle, para quien la vida de la nación a partir de la independencia, había mostrado que el indio, cuando está adecuado con el mestizo y con el blanco, es capaz de todo lo bueno y todo lo alto, afirmando que ésto lo habían demostrado numerosos indios notables, que figuran entre nuestros prohombres del pasado y del presente (recordemos tan sólo a Juárez y Cárdenas, este último presidente en ese momento), de manera, que si se dejaba que las cosas siguieran su curso, sólo era cuestión de tiempo, de siglos quizá, la completa incorporación:

\footnotetext{
«Se ha tratado de resolver el problema por medio de la educación o de la instrucción, pero es necesario confesar, que ésto es insuficiente, que el indio nada gana con aprender a leer y escribir, si no tiene qué leer ni para qué escribir y nada gana con aprender a contar, si sus problemas los puede resolver con los dedos ${ }^{76_{\text {» }}}$
}

En ese mismo artículo, Alfredo Del Valle cita a Emilio Rabasa, un intelectual positivista, miembro del grupo «Justo Sierra y Barreda», conductores de la política educativa oficial, protegidos durante el porfiriato, quien señalaba al respecto:

\footnotetext{
«Cuando los niños pobres indígenas concurren a un pueblo que tiene alumnos mestizos o criollos, empiezan por despertar y acaban por aprender tanto como los demás ...pero se debe al estímulo. Así van haciendo algunos ciudadanos por año, pero de la escuela que va a buscar al indio a sus montañas o en sus poblados primitivos, no da a la nación un sólo ciudadano ${ }^{77}$ »
}

Don Alfredo del Valle concluye en este trabajo proponiendo una serie de medidas necesarias para resolver la problemática general de la población mexicana y destaca los aspectos eugénicos y la educación:

\footnotetext{
76 Del VAlle R., Alfredo, (1940), «La Población Mexicana y la Eugenesia», Eugenesia, Tomo I, N ${ }^{\circ}$

77 RABASA, Emilio, citado en DEL VALLE R., Alfredo, (1940), p. 13.
} 6, p. 13. 


\title{
LA INFLUENCIA DE LA SOCIEDAD EUGÉNICA MEXICANA EN LA EDUCACIÓN
}

\begin{abstract}
«Eugenesia. ... debe mencionarse especialmente el Establecimiento del Matrimonio Eugénico, es decir de aquel que se orienta tratando de que las taras que traen los individuos no se sumen, sino que se equilibren y que eviten los matrimonios de aquellos que tengan grandes taras y que no garanticen los intereses de la especie y de la sociedad.

Sería de ambicionarse que la costumbre sancionara que los jóvenes, hombres y mujeres, periódicamente se hicieran análisis de sangre para comprobar la salud, ...y que los jóvenes casaderos exhibieran sus certificados....

Educación. Difusión tan amplia como sea posible de la cultura eugenésica y de una bien orientada y moral educación sexual, para que los jóvenes adquieran todo el sentido de responsabilidad que deben tener para con las generaciones venideras, para lograr el mejoramiento de la raza... tendiendo a hacerla fuerte, activa, bella, sana e inteligente ${ }^{78}$ 》
\end{abstract}

Plantea la incorporación de los indígenas a la vida nacional en un momento en que la política oficial es eminentemente indigenista; gran parte de las instituciones que operaban y operan en la actualidad en México, se crearon o intensificaron su trabajo a partir del cardenismo. En el editorial de Eugenesia de diciembre de 1939, se señala que la Sociedad Eugénica Mexicana (SEM), se preocupa, acorde con el movimiento eugenésico mundial, de los problemas que se refieren a «la higiene racial», se refuerza la concepción de los eugenistas mexicanos ortodoxos típicamente representados por Alfredo Saavedra, de que el progreso puede impulsarse con el mejoramiento económico y la cultura; pero que «un pueblo deficientemente constituído, desde el punto de vista de su salud hereditaria, es un conglomerado del que poco se puede esperar; ... la realización humana en el campo del trabajo y de la idea dependen de su mejor dotación hereditaria, ya que las lesiones que se reciben de los antepasados son taras que modifican radicalmente la conducta del hombre ${ }^{79}$ ».

En el editorial de Eugenesia de julio de 1941, que seguía a cargo de Don Alfredo Saavedra, se señala que cuanto se gaste en una obra sistemática de propaganda educativa, para despertar el interés por la salud y la conciencia colectiva hacia la responsabilidad de los descendientes, es el dinero mejor empleado:

«Si a nosotros nos preguntaran cuánto, por lo menos, quisiéramos para servir en la obra del mejoramiento inicial de la especie, diríamos que nos conformamos con una cantidad semejante a la que se emplea, por ejemplo, en una de tantas exposiciones agrícola-ganaderas, y eso ya sería algo que beneficiaría a la especie humana ${ }^{80 » \text {. }}$

Fernando de Ocaranza, Socio Honorario de la SEM, en su trabajo titulado «El Sentido Social de la Eugenesia», señalaba el problema fundamental respecto al material humano, basándose en tres aspectos fundamentales, en relación con la desigual-

78 Ibid., p. 14.

79 «Editorial», (1939), Eugenesia, Tomo I, pp. 1-2.

80 «Editorial», (1941), Eugenesia, Tomo II, № 21, p. 1. 
dad: el aspecto económico, el físico y el intelectual. Hablaba de la disímil distribución de la riqueza en nuestro país y destacaba los extremos: «la riqueza inútil y casi inconcebible de algunos y la dolorosa miseria de otros ${ }^{81}$ ». Para Ocaranza, «el biólogo -y para él el eugenista era biólogo fundamentalmente- debe estar directamente relacionado con los movimientos sociales contemporáneos, dado que los precedentes de dicho movimiento, tienen fundamento biológico, ya que las bases del individualismo, se encuentran precisamente en la teoría de la selección natural ${ }^{82}$ ». Es importante destacar que Ocaranza fue uno de los introductores de los principios mendelianos en los programas educativos del nivel superior en México. Ocaranza señala en este artículo la importancia de lograr el anhelado lema de la SEM, «Por una humanidad mejor», y afirma que el objetivo de la misma «no se dirige hacia un mejoramiento moral exclusivamente», sino que debe considerarse el aspecto biológico de la capacidad física e intelectual, como base para dicho mejoramiento ${ }^{83}$. Señala que el material humano de que se dispone en México, desde el punto de vista étnico, está formado por criollos, indios y mestizos, y establece una diferencia en torno a la herencia de los tres grupos, colocando en desventaja a los mestizos:

\footnotetext{
«...a título de resolución por demostrar,...los criollos poseen los defectos y cualidades de sus progenitores españoles; los indios los defectos y las cualidades de los remotos nativos; los mestizos, tan sólo los defectos del progenitor español y del indígena ${ }^{84 »}$
}

En términos generales, es claro el desconocimiento por parte de los eugenistas mexicanos respecto de los factores externos que no tienen influencia en el material hereditario, ya que muchos de ellos afirman que diversos compuestos tóxicos afectan los gametos, lo que implica una óptica de los factores hereditarios anterior a la concepción de Weismann respecto a la separación soma-germen y permite asegurar su ignorancia respecto a los principios mendelianos. Como vemos, en las publicaciones médicas mexicanas de las décadas de los treinta y cuarenta, un lugar especial lo ocupan la educación sexual y la profilaxis de las enfermedades venéreas, dado que representaba un serio problema de salud y asistencia pública en nuestro país. En el mes de mayo de 1941, en la convención celebrada para estudiar los Problemas de la madre y el niño, Alfredo Saavedra, director de la revista Eugenesia, presentó el trabajo «La Selección de los Generadores Humanos», en donde señalaba la obligación de las instituciones oficiales, que por medio de la ciencia debían orientar la responsabilidad sanitaria en todos sus aspectos; el cuidado integral y preventivo de la salud heredita-

81 OCARANZA, Fernando de, (1939), «El Sentido Social de la Eugenesia», Eugenesia, Tomo I, Núm. 2. p. 5 .
82 Ibid., p. 5.
83 Ibid., p. 6.
84 Ibid., p. 7. 


\section{LA INFLUENCIA DE LA SOCIEDAD EUGÉNICA MEXICANA EN LA EDUCACIÓN}

ria, que representaba a la postre lo que regía la conducta en todos sus aspectos morales, ligados íntimamente a la economía de la población, por lo que debía ser prioridad para las autoridades de salubridad; se debía analizar con seriedad lo que representaba la sanidad de los progenitores para el desarrollo de la vida normal del futuro ${ }^{85}$. Para el Dr. Saavedra,

«...la verdadera riqueza de un pueblo radica en el valor etnológico, los factores mesológicos [término que emplea para referirse a los factores ambientales, incluída la educación a los que confiere importancia secundaria al igual que Galton] dependen para su utilización y explotación de la potencialidad de los habitantes; el hombre está dotado para transformarlos haciéndolos útiles al progreso, gracias a la potencia inventiva y de trabajo el hombre se supera y la fuerza de él depende de su composición étnica.

Sería por demás curioso que a la fecha el criterio de política sanitaria no hiciera un esfuerzo para interesarse en resolver una cuestión que está íntima y fundamentalmente ligada a la salud racial.

...para lograr un desenvolvimiento armónico en la vida nacional, conociendo que la piedra angular, que el pivote alrededor del cual gira la vida es la contingencia hereditaria, que la insanidad y las deficiencias mentales, las toxicomanías, el alcoholismo la transmisión de lacras físicas y morales, la transmisión de enfermedades venéreas y las meramente hereditarias, son motivos serios que deben considerarse como factores que determinan situaciones anómalas en la conducta colectiva.

... para lograr el mejoramiento humano preventivamente, dos son las acciones que deben estimarse, la restricción para evitar que los indeseables lacrados sigan multiplicándose y el fomento para la reproducción de los bien dotados ${ }^{86}$ »

Es claro que Saavedra sí conocía, e intentaba promover con bastante precisión, los planteamientos eugenésicos de Galton, con respecto a las políticas sanitarias que debía impulsar el estado. Así, señala la importancia de los estudios familiares, la selección de los individuos mejor dotados y la limitación de la reproducción para los portadores de taras físicas y/o mentales.

Respecto al problema demográfico en los años cuarenta en México, Saavedra señalaba, al igual que reseñaban los trabajos sobre la problemática de la escasa densidad poblacional una década antes, la necesidad de incrementar la tasa de natalidad y reducir el índice de mortalidad en los menores de cinco años; pero afirmaba que el futuro de la política económica, dependía no sólo de un problema cuantitativo, sino de una «selección de la calidad», porque de otra forma se emplearían los recursos de la beneficencia sólo en paliar las necesidades de «tantos débiles que pesan sobre el estado», y en procurar «la reproducción de las familias bien dotadas, para substituir a

85 SAAVEDRA, Alfredo M. (1941), «La Selección de los Generadores Humanos. Trabajo presentado a la Convención para estudiar los problemas de la Madre y el Niño, en la Ciudad de México en Mayo de 1941», Eugenesia, Tomo II, No 19, pp. 11-14.

86 Ibid., p. 12. 
todos los deficientes que pululan por todas partes ${ }^{87} \gg$. Propone la creación de una oficina dedicada al estudio de los problemas de Higiene Racial, que investigue y señale medidas prácticas tanto de eugenesia positiva como negativa, que oriente y equilibre la buena calidad con la cantidad de la población; además, el establecimiento de la ficha biotipológica, en coincidencia con los eugenistas peruanos y argentinos, para señalar en cada caso concretamente cuando hay «indeseabilidad para la reproducción».

Dada la situación de México en un momento de revaloración del indio, de impulso a sólidos programas indigenistas, con un estado de corte socialista en lo educativo y en torno a las demandas sociales más sentidas, se observa en los escritos de Saavedra cierta cautela en sus planteamientos. Piensa que la miseria económica no debe considerarse como causa eficiente para aconsejar la supresión de la natalidad, ya que se puede resolver con una técnica adecuada de justicia económico-social. Pero con relación al establecimiento de la ficha biotipológica, sostiene que:

\footnotetext{
«... es más práctico señalar a los individuos inadecuados... desde el punto de vista sanitario, ya que en verdad y por lo pronto lo que se persigue no es constituir el grupo de los superdotados, que desde luego, no son el ideal eugénico, sino evitar a los deficientes biológicos que constituyen el problema básico...y procurar facilidades para la reproducción de los individuos normales, dentro de todos los biotipos ${ }^{88}$ »
}

Saavedra señala los casos genéricos más importantes, como factores cacogénicos: alcoholismo consuetudinario y toxicomanías; oligofrénicos y algunos vesánicos, los afectados de estigmas o enfermedades graves de carácter hereditario dominante; algunos delincuentes, no por el carácter de delincuencia en sí, sino por las taras neuropáticas susceptibles de transmitirse y que los hace socialmente inadaptados. Y señala su experiencia médica en el sentido de llegar a la conclusión de que múltiples casos de intoxicaciones graves - por sales de plomo- lesionan las «celdillas germinativas» y provocan «saturnismo». El empleo del término celdillas germinativas es afín a la óptica de Weismann, pero recordemos que para éste una alteración del soma no repercute en el germen, elemento central de su refutación a la tesis de la herencia de los caracteres adquiridos de Lamarck. Saavedra propone una amplia y eficiente acción de propaganda referente al alto sentido de responsabilidad humana que deben revestir todos los actos relacionados con la procreación, para que por medio de la convicción moral se seleccionaran los más altos atributos a través de las futuras generaciones. En este trabajo Saavedra concluye proponiendo a las autoridades sanitarias la creación de un Instituto de Investigación de la Genealogía Mexicana, que se

87 Ibid., p. 13.

88 Idem. 


\section{LA INFLUENCIA DE LA SOCIEDAD EUGÉNICA MEXICANA EN LA EDUCACIÓN}

abocara al estudio de la Higiene Racial, propuesta que fue rechazada, en la misma sesión en que la presentó.

La obra Doña Eugenesia y otros personajes ${ }^{89}$, reúne una serie de cuentos de higiene y educación sexual que seleccionó el Dr. Manuel González Rivera, --profesor de Educación Higiénica en la Escuela de Salubridad e Higiene, dependiente de la Secretaría de Salubridad Pública - que fue editado con la intención de que se distribuyese de manera gratuita entre los trabajadores del Departamento de Salubridad, especialmente entre los médicos y enfermeras que trabajaban en los años cuarenta en las zonas rurales. Dado que no fue posible obtener recursos para ello, se puso a la venta. La mayor parte de los cuentos que contiene esta obra versan alrededor del control de las enfermedades venéreas, de la herencia de la tuberculosis, de la obligatoriedad y garantía de salud de la descendencia gracias al análisis y consecuente certificado prenupcial, y del empleo de las clínicas gratuitas de salubridad para atender a los niños y madres. También se manejan en diversos cuentos, en tono moralista, argumentos contra el aborto.

\section{ALGUNAS CONSIDERACIONES SOBRE LA INFLUENCIA DE LA SEM.}

La SEM manifestó de múltiples formas su interés por los aspectos educativos relacionados con la salud reproductiva. Ejemplos claros de ello son los múltiples cursos dedicados a enfermeras y a trabajadoras sociales, y las publicaciones de divulgación, tanto para el gremio médico como para la población general, ediciones diseñadas con el interés de difundir «el arte científico de la eugenesia» y su concepción de «higiene racial».

Aunque la mayor parte de los eugenistas mexicanos poseían formación médica y recurrían reiteradamente para fundar su opinión a personajes como Mendel, Galton, de Vries y Weismann entre otros destacados genetistas, rara vez hacían alusión directa a sus teorías. Señalaban que dado que los factores que controlan y modulan la expresión hereditaria son «tan complejos», preferían no tocarlos. Es evidente, en general, su enorme desconocimiento de la genética incluso en los años cuarenta. Dentro de sus propuestas eugenésicas, se encuentra, en general, una buena carga de factores ambientalistas, postura contrapuesta a los planteamientos galtonianos; e impulsan todas las facetas de la puericultura, similar a la práctica de la eugenesia en Francia, lo que refleja la tradición de los intelectuales mexicanos, desde el origen del porfiriato, en cuanto a la valoración de la cultura francesa, por lo que otorgan un valor especial a la educación que deben tener los futuros padres respecto de su des-

89 GonZÁlez RIVERA, Manuel, (Compilador), (1943), Doña Eugenesia y otros personajes: Materiales de Educación Higiénica Popular. Cuentos, Talleres Tipográficos Modelo, S.A.,México, D.F. 
cendencia; tratan los problemas de control matrimonial y de la procreación, la importancia de la supervivencia, que refleja la preocupación por el elevado índice de mortalidad infantil en las décadas 30 y 40 en México.

Por otra parte, la influencia de la SEM en la promoción legislativa se expresa en diversas facetas. Respecto a la salud matrimonial, en la formalización de la «Ley de certificado prenupcial de 1935, Decreto No.1709»; en el reglamento de la campaña antivenérea de abril de 1940; en la derogación de la reglamentación de la prostitución y en múltiples programas de educación sexual y campañas de difusión y propaganda sobre la responsabilidad hacia la descendencia; lo mismo que se puso en práctica desde la educación básica de manera formal por la Secretaría de Educación Pública. $\mathrm{Su}$ influencia se observa también en las numerosas campañas de prevención de enfermedades venéreas y transmisión de caracteres psicopatológicos a través del Departamento de Salubridad Pública.

A pesar de sus numerosos discursos, sobre todo durante el cardenismo, en que se consideran los programas indigenistas de salud y educación como parte de las políticâs estatales prioritarias, la participación de la Sociedad Eugénica Mexicana en los programas indigenistas es prácticamente nula. Desgraciadamente, en 1940 el Departamento Autónomo de Asuntos Indígenas en que participaba Gamio, al desaparecer en los sucesores de Cárdenas la vocación indigenista, se burocratizó, perdió su orientación original y entró en decadencia a partir de 1941. 